\title{
ROLE OF PROPHYLACTIC SUPRAOMOHYOID NECK DISSECTION V/S USG ALONG WITH USG FNAC IN MANAGEMENT OF CLINICALLY T1 T2 NO SQUAMOUS CELL CARCINOMA OF BUCCAL MUCOSA
}

\author{
Megha Mittal1, Gaurav Agrawal'2, Amit Agrawal3, K. K. Agrawal \\ ${ }^{1}$ Assistant Professor, Department of Radiodiagnosis, GR Medical College, Gwalior. \\ ${ }^{2}$ Consultant, Department of Surgical Oncology, BIMR Oncology Centre, Gwalior. \\ ${ }^{3}$ Resident, Department of Radiotherapy, SRMS Hospital, Bareilly. \\ ${ }^{4}$ Consultant, Department of Oncology, BIMR Oncology Centre, Gwalior.
}

\begin{abstract}
\section{OBJECTIVES}

To address issues like role of SND in clinically negative neck, role of ultrasound and ultrasound-guided FNAC in staging of the neck and followup.

\section{STUDY DESIGN}

A randomized prospective study.

\section{SETTING \\ Mahavir Cancer Sansthan, Patna. \\ METHODS}

50 patients with carcinoma of the buccal mucosa with clinically negative neck (cT1T2N0) during May 2009 to May 2011 were included in study, after obtaining well-informed written consent. Patients were examined with real time scanner with probe heads of 7.5 MHz frequency transducer. The most suspicious lymph nodes were aspirated. If positive they were randomized to neck dissection arm. Patients were then randomized to observation arm and neck dissection arm. In neck dissection arm, who have not met most suspicious lymph node criteria have undergone SND (I-III) and who were positive on FNAC have undergone MRND II (IV). Correlation of clinicopathological variables with lymph node status was done. Patients were followed till printing of this poster. Followup visits were performed at 4-8 weeks interval. Apart from routine examination, USG was done in all patients in observation arm. For regional recurrence, MRND II was done. Data was analysed with SSPS 16.0 software windows.
\end{abstract}

\section{RESULTS}

A wait-and-see policy using USG and USG-FNAC has $8 \%$ recurrence rates with $100 \%$ salvage rates.

\section{CONCLUSION}

Prophylactic supraomohyoid neck dissection (Level I-III) is now an acceptable method of elective neck dissection in T1-T2 cancer of buccal mucosa with clinically N0 neck. A wait-and-see policy of the N0 neck after transoral tumour excision only seems feasible if a strict and accurate follow-up regimen can be provided.

\section{KEYWORDS}

Neck Dissection, USG.

HOW TO CITE THIS ARTICLE: Mittal M, Agrawal G, Agrawal A, et al. Role of prophylactic supraomohyoid neck dissection v/s USG along with USG FNAC in management of clinically T1 T2 N0 squamous cell carcinoma of buccal mucosa. J. Evolution Med. Dent. Sci. 2016;5(32):1749-1754, DOI: $10.14260 /$ jemds /2016/412

\section{INTRODUCTION}

Carcinoma of buccal mucosa is one of the most common cancer in Indian male and the incidence is particularly high in North India. Presence of lymph node metastases in the neck at the initial presentation is one of the single most important prognostic factor in outcome, in terms of local recurrence and survival. ${ }^{1}$ It is paramount to know in patients who are node negative (N0), whether they are truly negative or harbour occult metastases or micrometastases, because this can cause

Financial or Other, Competing Interest: None.

Submission 21-02-2016, Peer Review 26-03-2016,

Acceptance 01-04-2016, Published 21-04-2016.

Corresponding Author:

Dr. Megha Mittal,

Opposite old High Court,

Lashkar.

Gwalior.

E-mail: drmeghamittal@gmail.com

DOI: $10.14260 /$ jemds $/ 2016 / 412$ nodal recurrence if the neck is not addressed while treating the primary, on the other hand if patients are truly node negative the treatment of neck is unnecessary and leads to over treatment of the disease.

Clinical examination of neck is notoriously inaccurate in as many as $60 \%$ of cases, therefore employment of imaging technology like ultrasound and ultrasound-guided FNAC, Computed Tomography (CT) scan, Magnetic Resonance Imaging (MRI), Positron Emission Tomography (PET) scans are now currently utilized in evaluating clinically impalpable nodes with varying sensitivity and specificity.

Sentinel Lymph Node Biopsy (SLNB) is a minimally invasive, feasible and relatively accurate technique in staging of the neck.(2) and is gradually emerging as a staging procedure in N0 neck. In N0 neck various treatment policies are available; observation, elective irradiation or elective surgery with neck dissection.

The present study was conducted on T1 T2 N0 carcinoma of the buccal mucosa and we have tried to address issues like 
role of prophylactic supraomohyoid neck dissection in clinically negative neck, role of ultrasound and ultrasoundguided FNAC in staging of the neck, role of ultrasound and ultrasound-guided FNAC in followup and predictive factors for lymph node metastases.

\section{AIMS AND OBJECTIVES}

Aim of this study is to assess the patients with T1 T2 N0 squamous cell carcinoma of buccal mucosa with following objectives.

1. Study the role of prophylactic, i.e. elective supraomohyoid neck dissection in these patients.

2. Study the role of adding ultrasonography and ultrasoundguided FNAC to clinical examination in the routine workup of a node negative patient.

3. To study-does ultrasonography has a role in followup or is clinical examination sufficient.

4. Identify prognostic factors that may help identify a subset of patients at an increased risk of lymph node metastases.

\section{MATERIAL AND METHODS}

\section{Study Design}

This prospective study was carried out in the Department of Surgical Oncology with association of Department of Pathology and Radiology, Mahavir Cancer Sansthan, Phulwari Sharif, Patna, after being approved by Mahavir Cancer Sansthan Ethics Review Committee; 592 cases attended surgical OPD pertaining to oral cavity cancer; 156 patients were of carcinoma of buccal mucosa, out of these 50 patients with carcinoma of the buccal mucosa with clinically negative neck (cT1T2N0) who were admitted during May 2009 to May 2011 were included in the study after obtaining well informed written consent.

\section{Inclusion Criteria}

1. Patients above 18 years age and below 75 years.

2. Patients with histologically proven $\mathrm{T} 1$ or T2N0M0 squamous cell carcinoma of buccal mucosa.

3. Surgery is the preferred treatment and the primary tumour can be excised with clear margins via the peroral route.

4. No history of prior malignancy in the head and neck region.

5. No prior malignancy outside the head and neck region in the preceding 5 years.

6. Patient will be reliable for followup.

7. Understands and is able to give informed consent.

\section{Exclusion Criteria}

1. Patients with palpable neck nodes.

2. Prior radiotherapy or surgery for malignancy in the head and neck region.

3. Patients who received neoadjuvant chemotherapy.

4. Patients primarily treated with radiotherapy.

5. Peroral excision of tumour will compromise margins.

6. Patients refusing to participate in the study.

\section{METHODS}

\section{Clinical Examination}

Detailed history was taken and a thorough clinical examination was carried out.

\section{Ultrasound Examination}

Ultrasound examination was done with real time scanner with probe heads of $7.5 \mathrm{MHz}$ frequency transducer. The neck was examined longitudinally and transversely covering the neck region from the thoracic inlet and scaleneus muscles to the submental region anteriorly and retroparotid regions posteriorly. If nodes were present on ultrasound then level, number, size, shape (Longitudinal axis/transverse axis), nonhilar vascular pattern, echogenicity, necrosis, extracapsular extension and other characters were noted. The most suspicious lymph nodes (Table 1 ) in the first or second echelon were aspirated. A maximum of three lymph nodes per side were aspirated. Postoperative histopathology was correlated with ultrasound and ultrasound-guided FNAC findings.

\section{Surgical Procedure}

Emphasis will be to achieve a wide clearance with tumour free margins to obviate the need of subsequent radiotherapy to the primary, which would otherwise act as a confounding factor. Intraoperative healthy margin from tumour was measured in four directions with scale before and after excising the tumour. Tumour thickness was measured with scale after excision.

Patients randomized to neck dissection will undergo a standard supraomohyoid neck dissection that will involve clearance of nodal levels I, II, III.

\section{Postoperative Histopathology \\ Primary}

Postoperative specimen of primary tumour was examined under haematoxylin and eosin stain after preparing paraffin sections. Primary tumour size, grade, thickness, involved pathological tumour margin, perineural invasion and lymphovascular invasion were recorded.

\section{Lymph Nodes of Neck}

After retrieving lymph nodes separately from each level and sublevel following features were noted. Number of lymph nodes harvested in each neck dissection, number of lymph nodes at each level and sublevel were noted. Lymph nodes were fixed in $10 \%$ formalin and then serial sectioning of nodes with $2 \mathrm{~mm}$ cuts were done and examined under microscope with haematoxylin and eosin stain. Whether lymph nodes contained metastases, any extracapsular spread were looked for.

\section{Followup}

All patients were followed up till May 31, 2011. Followup visits were performed at 4 to 8 weeks interval. Patients were examined for any early or delayed complication, loco-regional recurrence and distant metastases. Ultrasound was done in both groups at each followup visit. Ultrasound guided FNAC was performed in suspicious lymph nodes.

\section{Statistical Analysis}

Statistical analysis was done with SSPS 16.0 software windows. Sensitivity and specificity of diagnostic tests were calculated using the standard formulas. P value calculated with univariate ANOVA test.

\section{OBSERVATION}

In present prospective study, 50 patients of carcinoma buccal mucosa who were clinically $\mathrm{N} 0$ were studied; 25 patients have undergone wide excision and supraomohyoid neck dissection under general anaesthesia and 25 patients have undergone wide excision alone under local anaesthesia.

Median age was 55 years in neck dissection arm and 53 years in observation arm. Major age group affected was between 41 and 60 years (31 patients; 62\%) in both arms. 
Male-to-female ratio was 4:1 in neck dissection arm; Male-tofemale ratio was 3:1 in observation arm. Out of 25, 24 (96\%); 22 (88\%) patients were tobacco chewers, 12 (48\%); 10 (40\%) were smokers and 5 (20\%); 5 (20\%) were habitual to alcohol in neck dissection arm and observation arm respectively.

The commonest associated premalignant condition was leukoplakia, which was present in 7 (28\%); 4 (16\%) patients of neck dissection arm and observation arm respectively, submucous fibrosis was present in $3(12 \%) ; 3(12 \%)$ patients of neck dissection arm and observation arm respectively and erythroleukoplakia in 1 (4\%) patient of neck dissection arm; 9 (36\%); 11 (44\%) patients were T1, 16 (64\%); 14 (52\%) were $\mathrm{T} 2$ in neck dissection arm and observation arm respectively.

Ultrasound was done in all 50 patients; ultrasound detected lymph nodes in 27 (54\%) patients, 2/27 patients have suspicious lymph nodes. Size $\geq 8 \mathrm{~mm}$ was present in $2 / 27$, longitudinal/transverse ratio $\leq 2$ was present in $2 / 27$ patients, 3 or more normal looking lymph nodes grouped in high risk area were present in 2/27 patients. Other suspicious features like non-hilar vascular pattern, parenchymal granular echoes, necrosis, extracapsular spread were absent in $27 / 27$ patients. Ultrasound FNAC was positive in both patients with suspicious lymph node category. These 2 patients were enrolled in neck dissection arm. Ultrasound examination using suspicious lymph node criteria showed sensitivity of $66 \%$, negative predictive value of $95.6 \%$, specificity of $100 \%$ and positive predictive value of $100 \%$ (Table 2 ).

25 patients underwent supraomohyoid neck dissection. Mean yield of lymph node per SOHND was 10.76 nodes per neck. Distribution of nodes according to level were level Ia 13 (4.8\%), level Ib 66 (24.5\%), level IIa 90 (33.45\%), level IIb 24 (8.9\%), level III 76 (28.25\%). Average yield of lymph node per each sublevel were level Ia 0.5 , level Ib 2.6, level IIa 3.6, level IIb 0.96 , level III 3.04. Out of 25 patients 3 patients had positive lymph nodes, total 7 lymph nodes were positive, 2 (28.5\%) in level Ib, 4 (57.1\%) in level IIa and 1 (14.28\%) in level IIb.

In node negative group, male:female ratio was $3.4: 1$; in node positive group all 3 positive patients were males. All patients in both node negative and node positive groups were tobacco chewers; 9 patients in node negative group had pT1 stage and no patient in node+group had pathological T1 stage; 13, 3 patients in node- and node+ had pT2 stage respectively; $13 / 22,9 / 22$ patients in node- group were Grade I and Grade II respectively; $3 / 3$ patients in node+ group were Grade II. Lymphatic permeation was present in $1 / 3(33 \%)$ patients of node+ group; node- group did not have lymphatic permeation. No patients in both groups have vascular invasion and perineural invasion (Table 3). Median tumour thickness in neck dissection arm was $4 \mathrm{~mm}$. The node positive group had 3 patients with $6 \mathrm{~mm}, 8 \mathrm{~mm}, 13 \mathrm{~mm}$ tumour thickness (Table 4).

After neck dissection 2 (8\%) patients had angle of mouth drooping. Shoulder dysfunction was present in $3(12 \%)$ patients, which recovered in 3 weeks. Wound dehiscence was minor in $2(8 \%)$ patients, which healed and major in none; 16 $(64 \%)$ patients had numbness of skin flaps with no relief yet; $2(8 \%)$ had burning of skin which recovered in six weeks; 1 patient had parotid fistula which healed in 4 weeks. Postoperative haemorrhage was present in none. No patient had contracture of neck.

Average hospital stay in neck dissection arm was 9 days and in observation arm was 1 day.
Followup was done for 2 years; total number of patients lost to followup was $3(12 \%) ; 2(8 \%)$ in neck dissection arm and observation arm respectively. Median duration of followup was 12; 11 months in neck dissection arm and observation arm respectively. Minimum followup was 4; 4 months in both arms. Maximum followup was 23; 20 months in neck dissection arm and observation arm respectively. Mean disease free survival was 13 months; 11 months in neck dissection arm and observation arm respectively; 2 patients had regional recurrence in observation arm at 17, 18 months detected on ultrasound confirmed with USG-guided FNAC and no regional recurrence in neck dissection arm. No patients in both arms had local and distant recurrence.

Two patients who had regional recurrence have undergone modified radical neck dissection type II with 100\% salvage rates. Ultrasound suspicious characteristics like size $\geq 8 \mathrm{~mm}, \mathrm{~L} / \mathrm{T}$ ratio $\leq 2,3$ or more normal looking lymph nodes grouped in high risk area were present in both patients, extracapsular spread was present in 1 patient whereas nonhilar vascular pattern, parenchymal granular echoes, necrosis were present in none. Distribution of lymph nodes as per level was level Ia 4 (7.5\%), level Ib $9(16.9 \%)$, level IIa 11 (20.7\%), level IIb 6 (11.3\%), level III 9 (16.9\%), level IV 6 (11.3\%), level V 8 (15.09\%). Average yield of lymph nodes per neck was Ia:2, Ib:4.5, II:5.5, III:3, IV:3, V:4. Distribution of positive lymph nodes was level Ib 3 (42.8\%), level IIa 3 (42.8\%), level III 1 (14.3\%).

Patients in recurrence group, both were males and tobacco chewers. Pathological stage was T1 in both patients; 1 patient had Grade I another had Grade II. No patient had lymphatic permeation, vascular invasion and perineural invasion. Tumour thickness was $4 \mathrm{~mm}$ in one patient and $5 \mathrm{~mm}$ in another patient (Table 5).

\section{DISCUSSION}

The appropriate management of the clinically N0 neck among patients with squamous cell carcinoma of the oral cavity continues to be a therapeutic challenge.

The key question in the decision making between elective neck treatment or observing the neck is whether there is a difference in prognosis between these 2 policies. There have been many retrospective studies. ${ }^{3-5}$ most of which have shown an advantage of elective treatment. Only 3 randomized prospective studies. ${ }^{6-8}$ have been performed and none of these showed a statistically significant difference in survival. The intention of this present study is not to advocate one approach over another, but rather to assess the efficacy of selectively treating the neck based on USG and USG-guided FNAC.

Many studies have advocated that management of the neck be included in the overall treatment strategy for the primary cancer rather than being viewed in isolation.

The principal aim of treating the clinically negative neck, either by surgery or radiotherapy is to maximize the rate of control of disease in the neck. Whether this contributes to improved survival remains unproven. However, this is of little consequence, because there are several benefits. Among surgically treated patients, selective neck dissection facilitates the use of microvascular free tissue transfer by allowing the isolation of recipient blood vessels in the neck. In addition, the useful pathological information about the extent of neck disease can be obtained, facilitating selection of patients for adjuvant neck irradiation or systemic therapy. 
Supraomohyoid neck dissections (Levels I-III) is widely accepted as the appropriate selective neck dissection for patients with oral cavity cancer and a clinically negative neck. Christopher J. Obrien. ${ }^{2}$ in his study showed that 62 patients with pT1 stage (11) and pT2 stage (51) who have undergone supraomohyoid neck dissection had 3 (27\%) and 18 (35\%) positive lymph nodes; distribution pattern for positive lymph nodes for level I, II, III was $10 \%, 18 \%, 8 \%$ respectively. In present study 25 patients with pT1 stage (9) and pT2 stage (16) who have under gone supraomohyoid neck dissections had $0(0 \%)$ and $3(19 \%)$ positive lymph nodes; distribution pattern of positive lymph nodes was level Ib 4\%, level IIa 8\%, level IIb $4 \%$ whereas level Ia, III were not involved.

The aim of another approach, i.e. staging and reserving definitive treatment for those who are found to have subclinical disease in the neck is to find a staging technique sensitive enough to reduce the risk of occult metastases to $<20 \%$, i.e. have negative predictive value $>0.8$. Risk of occult metastases in T1 and T2 cancer of buccal mucosa is $<20 \%$ and $20 \%-30 \%$ respectively. For an investigation with a specificity of $100 \%$, if occult metastases occur in $30 \%$ of patients, a sensitivity of at least $42 \%$ is required to avoid treatment. In present study sensitivity of ultrasound using ultrasound suspicious lymph node category is $66 \%$ with specificity of $100 \%$ with negative predictive value of $95.6 \%$, which is acceptable to be used as a staging imaging in observation arm.

In the present study, failure rate in the neck is $8 \%$ with $100 \%$ salvage rates compares favourably with the incidence of occult metastases quoted in the literature for patients treated with transoral tumour excision and a wait and see policy for the neck. ${ }^{3-11}$ (Table 6). In all these studies, in which only palpation is used to initially stage the neck, the recurrence rate in the neck is between $24 \%$ and $57 \%$ (Mean 32\%) (Table 6). In the study of Brekel et al. 1999 failure rate was $18 \%$ because he has used USG and USG FNAC for staging N0 neck. Our low recurrence rate can be explained by the initial use of USG suspicious lymph node criteria and USG-FNAC that diminishes the risk of occult metastases.

An important issue for the prognostic impact of a waitand-see policy is the salvage rate in case of neck recurrences. Our results show that with USG suspicious lymph node criteria and USG-FNAC during follow-up, it is possible to detect a significant percentage of neck recurrences in an early stage. In the literature, the reported salvage rate varies from as low as $27 \%$ to $82 \%$ (Average, $50 \%$ ) after a regional recurrence (Table 6).3-11 In this study we found a salvage rate of $100 \%$, although our followup period is still limited.

As the prognosis is closely related to the metastatic burden in the neck as well as to the presence of extranodal spread, the delay between the treatment of the primary tumour and the neck is probably crucial. To keep this delay as short as possible, the intervals between followup visits should be kept short, especially in the firstand second years. Although this implies an extra workload in the outpatient clinic, it is mandatory if a wait and see policy for the neck is conducted. In our series of patients, USG and USG-FNAC was used during followup every 8 weekly.

In the present study using tumour thickness cut off of 4 $\mathrm{mm}, \mathrm{P}$ value was significant $(\mathrm{p}<0.0001)$ and was the only predictor of nodal metastases.
The predictive capacity of tumour thickness in carcinoma of the oral cavity is well established; however, considerable debate exists over the most appropriate cut-off value to use in the application of elective neck dissection. Currently, there is no universally accepted method for measuring tumour thickness and this accounts in part for the different cut-off values described in the literature ranging from $1.5 \mathrm{~mm}$ to 8 $\mathrm{mm}$.

In present study there were nine pT1, sixteen pT2 patients. A total no. of 3 patients were found to have lymph node metastases after pathological examination, all 3 patients were pT2 stage, 3/16 (19\%) patients had nodal metastases in pT2 stage. Jonathan R. Clark et al. in their study showed 15\%, $22 \%$ nodal metastases in pT1, pT2 stage respectively. ${ }^{12}$ Christopher J. 0'Brien. ${ }^{2}$ in their study showed $27 \%$, 35\% nodal metastases in pT1, pT2 stage respectively. Lymph node metastases were increased as T stage of tumour increased.

Iype EM et al [2008].13 in a study of carcinoma buccal mucosa in young adults showed 18 (39\%) were welldifferentiated tumours, $14 \quad(30 \%)$ were moderately differentiated tumours and $1(2 \%)$ was poorly differentiated tumour. Differentiation was not recorded in 13 patients (28\%); $26 \%$ of well-differentiated tumours, $21.7 \%$ of moderately differentiated tumours and $40 \%$ of poorly-differentiated tumours had positive nodes pathologically. In present study 3 patients were lymph nodes positive, out of which $3 / 3$ (100\%) were moderately differentiated. It can be seen that moderately differentiated tumours showed increased propensity for lymph node metastases than well-differentiated tumours. It can be seen that with increasing grade, prevalence of lymph node metastases was increased.

In present study, there was a mean shrinkage of $1.25 \mathrm{~mm}$. This shrinkage is important when post-operative radiotherapy is given for close margin. This shrinkage raises the question whether post-operative radiotherapy for an indication of close margin should be based on intraoperative margin or postoperative margin.

\begin{tabular}{|ll|}
\hline 1. & Size $\geq 8 \mathrm{~mm}$ \\
\hline 2. & L/T ratio $\leq 2$ \\
\hline 3. & Non-hilar vascular pattern \\
\hline 4. & Parenchymal granular echoes \\
\hline 5. & Necrosis \\
\hline 6. & Extracapsular spread \\
\hline $\begin{array}{r}\text { 7. } \\
\text { nodes grouped in a high risk area }\end{array}$ \\
\hline \\
$\quad$ Table 1: US Features Suggestive of Lymph \\
Node Metastases Suspicion
\end{tabular}

\begin{tabular}{|c|c|}
\hline No & Ultrasound \\
\hline Sensitivity & $66 \%$ \\
\hline Specificity & $100 \%$ \\
\hline Positive predictive value & $100 \%$ \\
\hline Negative predictive value & $95.6 \%$ \\
\hline Table 2 : Statistics of Ultrasound \\
\hline
\end{tabular}




\begin{tabular}{|c|c|c|c|c|}
\hline & Node - & $\mathbf{\%}$ & Node+ & $\mathbf{\%}$ \\
\hline Gender & & & & \\
\hline Male & 17 & $77.30 \%$ & 3 & $100 \%$ \\
\hline Female & 5 & $22.70 \%$ & 0 & $0 \%$ \\
\hline Tobacco & & & & \\
\hline Yes & 22 & $100 \%$ & 3 & $100 \%$ \\
\hline No & 0 & $0 \%$ & 0 & $0 \%$ \\
\hline pT stage & & & & \\
\hline T1 & 9 & $40.90 \%$ & 0 & $0 \%$ \\
\hline T2 & 13 & $59.10 \%$ & 3 & $100 \%$ \\
\hline Grade & & & & \\
\hline I & 13 & $59.10 \%$ & 0 & $0 \%$ \\
\hline II & 9 & $40.90 \%$ & 3 & $100 \%$ \\
\hline $\begin{array}{c}\text { Lymphatic } \\
\text { permeation }\end{array}$ & & & & \\
\hline Present & 0 & $0 \%$ & 1 & $33 \%$ \\
\hline Absent & 22 & $100 \%$ & 2 & $67 \%$ \\
\hline $\begin{array}{c}\text { Vascular } \\
\text { invasion }\end{array}$ & & & & \\
\hline Present & 0 & $0 \%$ & 0 & $0 \%$ \\
\hline $\begin{array}{c}\text { Absent } \\
\text { Perineural } \\
\text { invasion }\end{array}$ & 22 & $100 \%$ & 3 & $100 \%$ \\
\hline $\begin{array}{c}\text { Present } \\
\text { Absent }\end{array}$ & 0 & $0 \%$ & 0 & $0 \%$ \\
\hline $\begin{array}{c}\text { Table 3: Correlation of Clinical and Pathological } \\
\text { Variables with Lymph Node Status n=25 }\end{array}$ \\
\hline
\end{tabular}

\begin{tabular}{|c|c|c|}
\hline $\begin{array}{c}\text { Tumour } \\
\text { Thickness }\end{array}$ & $\begin{array}{c}\text { Neck Dissection } \\
\text { Arm }\end{array}$ & $\begin{array}{c}\text { Node Positive } \\
\text { Group }\end{array}$ \\
\hline $\begin{array}{c}>2 \mathrm{~mm} \\
\mathbf{m m}-\leq 3 \\
\mathrm{~mm}\end{array}$ & 4 & 0 \\
\hline $\begin{array}{c}>3 \mathrm{~mm}-\leq 4 \\
\mathrm{~mm}\end{array}$ & 8 & 0 \\
\hline $\begin{array}{c}>4 \mathrm{~mm}-\leq 5 \\
\mathrm{~mm}\end{array}$ & 2 & 0 \\
\hline $\begin{array}{c}>5 \mathrm{~mm}-\leq 6 \\
\mathrm{~mm}\end{array}$ & 2 & 1 \\
\hline $\begin{array}{c}>6 \mathrm{~mm}-\leq 7 \\
\mathrm{~mm}\end{array}$ & 3 & 0 \\
\hline $\begin{array}{c}>7 \mathrm{~mm}-\leq 8 \\
\mathrm{~mm}\end{array}$ & 2 & 1 \\
\hline \multicolumn{2}{|c|}{1} & 1 \\
\hline \multicolumn{2}{|c|}{ Table 4: Correlation of Tumour Thickness } \\
\multicolumn{2}{|c|}{ with Lymph Node Status } \\
\hline
\end{tabular}

\begin{tabular}{|c|c|}
\hline $\begin{array}{c}\text { Lymphatic } \\
\text { permeation }\end{array}$ & 0 \\
\hline Present & \\
\hline $\begin{array}{c}\text { Vascular } \\
\text { invasion }\end{array}$ \\
\hline Present & 0 \\
\hline $\begin{array}{c}\text { Perineural } \\
\text { invasion }\end{array}$ \\
\hline Present & 0 \\
\hline Tumour \\
thickness
\end{tabular}

\begin{tabular}{|c|c|c|}
\hline Series & $\begin{array}{c}\text { No. of Patients } \\
\text { observed }\end{array}$ & $\begin{array}{c}\text { Salvaged No. } \\
\text { (\%) }\end{array}$ \\
\hline $\begin{array}{c}\text { Kligerman } \\
\text { et al., 1994 }\end{array}$ & 33 & $3(27)$ \\
\hline Ho et al.,1992 & 28 & $3(30)$ \\
\hline $\begin{array}{c}\text { Fakih } \\
\text { et al., 1989 }\end{array}$ & 40 & $7(30)$ \\
\hline $\begin{array}{c}\text { Cunningham } \\
\text { et al., 1986 }\end{array}$ & 43 & $9(50)$ \\
\hline $\begin{array}{c}\text { McGuirt et al., } \\
\text { 1995 }\end{array}$ & 103 & $22(59)$ \\
\hline $\begin{array}{c}\text { Khafif } \\
\text { et al., 1991 }\end{array}$ & 396 & $53(59)$ \\
\hline $\begin{array}{c}\text { Vandenbrouck } \\
\text { et al., 1980 }\end{array}$ & 36 & $14(82)$ \\
\hline $\begin{array}{c}\text { Brekel } \\
\text { et al., 1999 }\end{array}$ & 77 & $10(71)$ \\
\hline $\begin{array}{c}\text { Table 6: Summary of Results in Several Series of } \\
\text { Clinically No. Patients in whom a Wait and See } \\
\text { Policy for the Neck was conducted and the Primary } \\
\text { Tumour was treated by Transoral Excision. }{ }^{3-11}\end{array}$ \\
\hline
\end{tabular}

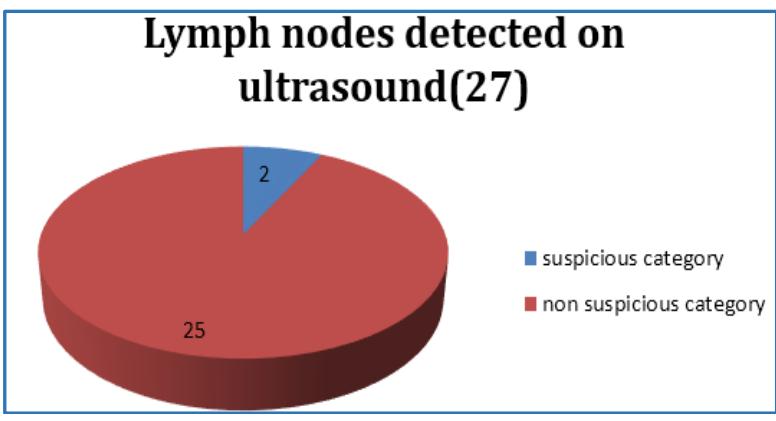

\begin{tabular}{|c|c|}
\hline & $\begin{array}{c}\text { Number of Patients with } \\
\text { Regional Recurrence }\end{array}$ \\
\hline Gender & 2 \\
\hline Male & 0 \\
\hline Female & 2 \\
\hline Tobacco & 0 \\
\hline Yes & \\
\hline No & 2 \\
\hline pT stage & 0 \\
\hline T1 & \\
\hline T2 & 1 \\
\hline Grade & 1 \\
\hline I & \\
\hline II & \\
\hline
\end{tabular}

Fig. 1: Number of Patients in whom Lymph Nodes were detected on Ultrasound

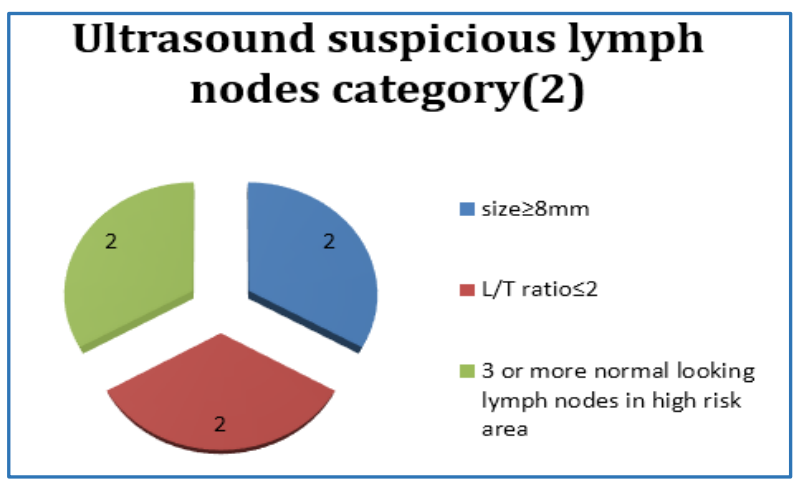

Fig. 2: Characteristics of Lymph Nodes in Ultrasound Suspicious Category 


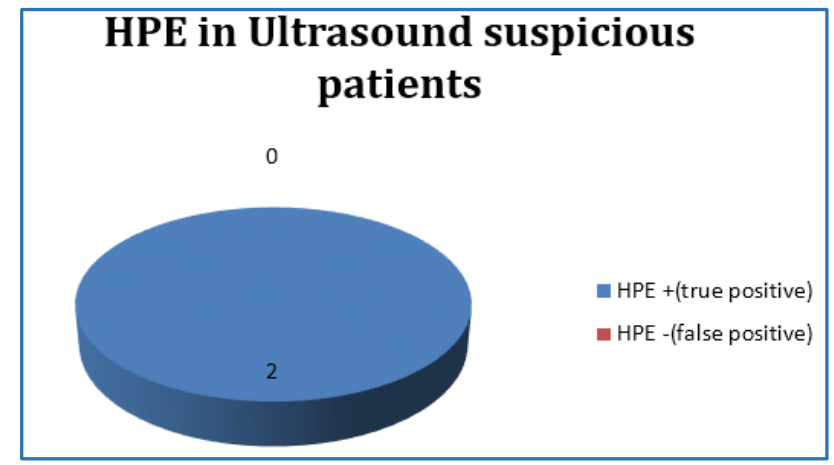

Fig. 3: Correlation of Histopathology with Ultrasound in Ultrasound Suspicious Patients

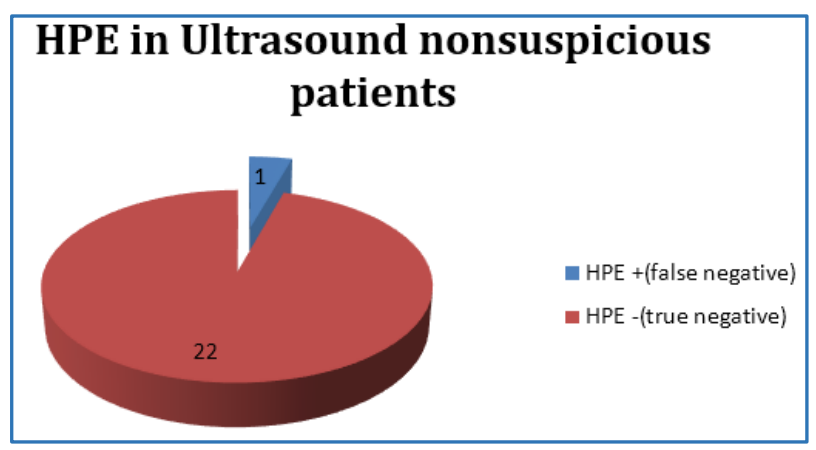

Fig. 4: Correlation of Histopathology in Ultrasound Nonsuspicious Patients

\section{SUMMARY AND CONCLUSION}

1. Prophylactic supraomohyoid neck dissection (Level I-III) is now an acceptable method of elective neck dissection in T1-T2 cancer of buccal mucosa with clinically N0 neck. In present study, this arm has produced good results with minimal morbidity.

2. A wait-and-see policy of the N0 neck after transoral tumour excision only seems feasible if a strict and accurate follow-up regimen can be provided. The moderate rate of occult metastases and high rate of neck salvage in this study warrant further use of this policy. Prognosis in these patients is comparable with that reported for patients treated with elective neck dissection. A strict follow-up with USG suspicious lymph node criteria and USG-FNAC requires motivation and good instruction to the patient as well as the skill of a well-trained ultrasonographer dedicated to do repeated examinations and aspirations of small lymph nodes.

3. In observation arm, all wide excisions were done under local anaesthesia as compared to neck dissection arm where general anaesthesia was used. Average hospital stay was 1 day in observation arm as compared to 9 days in neck dissection arm. Observation arm is less morbid and more cost effective for patients.
4. Prognostic variables like tumour thickness, pT stage, grade can predict lymph node metastases.

\section{REFERENCES}

1. Jadhav KB, Gupta N. Clinicopathological prognostic implicators of oral squamous cell carcinoma:need to understand and revise. N Am J Med sci 2013;5(12):6719.

2. O’Brien CJ, Traynor SJ, McNeil E, et al. The use of clinical criteria alone in the management of the clinically negative neck among patients with squamous cell carcinoma of the oral cavity and oropharynx. Arch otolaryngology Head and Neck surgery 2000;126(3):360-5.

3. Spiro RH, Strong EW. Epidermoid carcinoma of the oral cavity and oropharynx: elective vs therapeutic radical neck dissection as treatment. Arch Surg 1973;107:382-4.

4. Nahum AM, Bone RC, Davidson TM. The case for elective prophylactic neck dissection. Laryngoscope 1977;87(4Pt1):588-99.

5. Cunningham MJ, Johnson JT, Myers EN, et al. Cervical lymph node metastasis after local excision of early squamous cell carcinoma of the oral cavity. Am J Surg 1986;152(4):361-6.

6. Vanden Brouck C, Sancho-Garnier H, Chassagne D, et al. Elective versus therapeutic radical neck dissection in epidermoid carcinoma of the oral cavity: results of a randomized clinical trial. Cancer 1980;46(2):386-90.

7. Kligerman J, Lima RA, Soares JR, et al. Supraomohyoid neck dissection in the treatment of T1/T2 squamous cell carcinoma of oral cavity. Am J Surg 1994;168(5):391-4.

8. Fakih AR, Rao RS, Patel AR. Prophylactic neck dissection in squamous cell carcinoma of oral tongue: a prospective randomized study. Semin Surg Oncol 1989;5(5):327-30.

9. Ho CM, Lam KH, Wei WI, et al. Occult lymph node metastasis in small oral tongue cancers. Head Neck 1992;14(5):359-63.

10. McGuirt WF, Johnson JT, Myers EN, et al. Floor of mouth carcinoma: the management of the clinically negative neck. Arch Otolaryngol Head Neck Surg 1995;121(3):278-82.

11. Khafif RA, Gelbfish GA, Tepper P, et al. Elective radical neck dissection in epidermoid cancer of the head and neck: a retrospective analysis of 853 cases of mouth, pharynx, and larynx cancer. Cancer 1991;67(1):67-71.

12. Jonathan R Clark, Natalie N, Jason H Franklin, et al. Otolaryngology-head and neck surgery. Science Direct 2006;135(5):748-53.

13. Elizabeth Mathew Iype, Paul Sebastian, Aleyamma Mathew, et al. The role of selective neck dissection (I-III) in the treatment of node negative (N0) neck in oral cancer. Oral Oncol 2008;44(12):1134-8. 